\title{
Views of life and sense of identity in people with Alzheimer's disease
}

\author{
ANDERS WESTIUS*, KJELL KALLENBERG* \\ and ASTRID NORBERGं ${ }^{\dagger}$
}

\begin{abstract}
Making it possible for people with Alzheimer's disease to retain a sense of identity during the process of the disease poses a great challenge to care-givers, professionals and family carers. The aim of this study is to elucidate the role of the view of life of people with Alzheimer's in framing their sense of identity. Is their view of life a vital aspect of their sense of identity? 'View of life' was interpreted as a vital aspect of sense of identity, understood as the individual's beliefs about their life history and about the attributes that characterised them. Twenty-one people with mild to moderate stages of Alzheimer's disease were interviewed about their life story. The narratives were interpreted using a phenomenological hermeneutic method. By telling their life story, the participants also narrated their view of life, i.e. their conception of reality, their central system of values and their basic emotional attitudes. By their own accounts, the origins of the narrators' central values and basic emotional attitudes were established in early life. They also expressed a sense of meaningfulness and continuity when looking back on their lives. The findings suggest that for a care-giver or confidant, having knowledge of a person with dementia's view of life is valuable when seeking to confirm that person's sense of identity.
\end{abstract}

KEY WORDS - Alzheimer's disease, identity, life story, view of life, interviews, phenomenological hermeneutics.

\section{Introduction}

The central question addressed in this study is the connection among people with Alzheimer's disease (AD) between their 'view of life' or 'life view' and their sense of identity. Drawing on $2 \mathrm{I}$ interviews with people with mild to moderate $\mathrm{AD}$ about their life stories and views of life, this paper examines from both philosophical and existential perspectives a number of concepts that may help explain their view of life, e.g. personhood, identity,

* School of Health and Medical Sciences, Örebro University Hospital, Örebro, Sweden.

$\dagger$ Department of Nursing, Umeå University, Umeå and Department of Palliative Research, Ersta Sköndal University College, Stockholm, Sweden. 
mind, meaning and relationships ( $c f$. Coleman and Mills 200r; Harrison I993; Hughes, Louw and Sabat 2006). There have been several precursor studies. Kihlgren (1992) studied ways of caring for people with dementia that promoted the individual's integrity. Kitwood's ground-breaking work on person-centred dementia care (e.g. Kitwood I993, I997; Kitwood and Bredin 1992) inspired many studies of how personhood and self-identity can be recognised, strengthened and made a central concern (e.g. Jones and Miesen 1997; Mills 1997; Penrod et al. 2007; Schenk et al. 2002; Woods 200I).

The concepts of 'self' and 'identity' may be seen as synonymous and are so treated in this paper. The function of reminiscence and life review work concerning identity maintenance has also been discussed (Coleman 2005; Rathbone, Moulin and Conway 2008). For many elderly people, faith and spirituality play a major role in their life reviews and for the sense of identity (Melia 1999; Staude 2005), and several studies have examined spirituality in the context of dementia disease, with most focusing on pastoral care (Elliot 1997; Everett I996; Hellen I994; Richards I990; Stuckey 2003; Webb 200I). As often in the discourse about life and health, in these studies personal beliefs are seen exclusively as expressions of religious faith or spirituality.

In the present study, religious faith is understood as the belief in a personal God, while spirituality is the belief in some kind of spiritual life force. To the best of our knowledge, no scientific studies with a more comprehensive definition of personal life view and identity in people with dementia have previously been published. In this paper, 'view of life' is understood in a broad sense: every person has a view of life in which spiritual beliefs may or may not be a part. Scientific studies in which people with dementia disease express their view of life are also scarce. In an exploratory British study on spirituality and faith among people with dementia, Jolley et al. (2005) reported that the participants rated their personal beliefs as strong and important in their daily lives. In the United States of America, McFadden, Ingram and Baldauf (2000) studied expressions of values and feelings among people with advanced dementia disease and found that they acted or tried to act according to their ethical values.

Alzheimer's disease has been described as a threat to the self (Clare 2003). Indeed some professionals and relatives at times characterise people with $\mathrm{AD}$ as lacking a sense of self, and some evidence for the negative outcome is available (e.g. Orona I990; Karner and Bobbit-Zeher 2006; Ronch 1996). According to Fontana and Smith (r989), the mind of persons with $\mathrm{AD}$ becomes devoid of content at an early stage. Other research evidence and commentators, however, indicate that people with moderate 
to severe AD preserve a sense of personal identity. Sabat and Harré (1992) and Sabat and Collins (I999) proposed that people with late-stage AD can be understood as 'subjects driven by meaning'.

\section{Topic and objectives}

We have recently published a related study from the same sample of informants that showed that the personal views of life of people with moderate $\mathrm{AD}$ can be understood in the frame of their life story (Westius, Andersson and Kallenberg 2009). Their view of life was neither erased nor, in their own opinion, had it been significantly altered during their adult life. That paper did not address, however, the issue of whether their view of life was a vital component of their sense of identity, which is the objective of the present study. Put another way, this paper concentrates on the question, 'do people with mild to moderate AD themselves regard their personal life views as a vital aspect of their sense of identity?'

\section{Theoretical considerations}

\section{View of life}

A person's 'view of life' is defined as 'the theoretical and value-oriented assumptions that constitute or have a decisive influence on a comprehensive view of man and the world and that build a central value system and express a basic emotional attitude toward life' (Jeffner I988 $a$ : I3). There are close links among the three components. Central values, for example, may be motivated or supported by theoretical assumptions regarding the world and the essence of being a human. The central value system consists of norms and values fundamental to an individual, e.g. ethical and ideological principles. Basic emotional attitudes, an emotional predisposition to respond in a certain way to crises or other significant events, are thought to be constant throughout life (Jeffner I988 $b$ ). They are revealed in people's responses to the question, 'How do you feel about life?' (Kallenberg, Bråkenhielm and Larsson i996).

Intrinsic to a person's view of life are certain perspectives that fulfil both selective and interpretative functions in people's formulation of their sense of self. The individual's view of life guides both what is selected as important in forming his or her conception of reality and how it is interpreted. The central value system comprises ethical, political and aesthetic norms and values that are central to us, in the respect that they are influenced by and have influence on our identity (Andersson 2006). It is plausible that when the norms and values that are part of an individual's 
central value system are threatened, the person will act to protect them because of their importance to his or her sense of identity (Andersson 2006). Similar to the basic emotional attitudes, the central values of an individual tend to be stable over time (Jeffner 1978). This conception of view of life is more fully elaborated in the mentioned companion paper, 'View of life in persons with dementia' (Westius, Andersson and Kallenberg 2009).

\section{Identity}

From a social constructionist point of view, Harré (I991, I998) described a model in which identity is understood as a sort of trinity. Self $I$, the self of personal singularity, is 'experienced as the continuity of one's point of view in the world of objects in space and time. This is usually coupled with one's sense of agency, in that one takes oneself as acting from that very same point' (Sabat and Harré i992: 445). According to Sabat (2007), the existence of Self I in people with AD is evident in their continued use of the pronouns $I$ and $m e$, or through body language that indicates that they look upon themselves as subjects, as themselves. The self of personal singularity is broadly stable into the late stages of $\mathrm{AD}$ (Fazio and Mitchell 2009; Sabat 2001, 2007; Tappen et al. 1999).

Self 2 derives from a person's life history and from the physical and mental attributes that characterise them and their beliefs about these attributes: for example, thoughts on what sort of person they are and what traits of personality characterise them. This dimension of identity is connected to autobiographical memory, including the person's general knowledge of names, places and facts (semantic memory), as well as memories of personally-significant events (episodic memory). Self 2 may therefore be expected, in part, to be vulnerable to the progressive degeneration of cognitive memory. Addis and Tippett (2004) suggested that the ability to recall memories of childhood and early adolescence is vital for a preserved sense of identity. Klein and colleagues (Klein, Chan and Loftus 1999; Klein, Cosmides and Costabile 2003; Klein et al. 2002), however, found that part of a person's sense of identity, namely a person's knowledge of his or her traits of character, can be preserved without any retrievable episodic memory.

With reference to the above social-constructionist conceptual framework of identity, it is plausible to envision a person's view of life as a significant part of her or his beliefs about themselves and their world (Self 2). We also assume close connections between Self 2, autobiographical memory and narrative identity. A narrative understanding of personal identity focuses on how people present their identity-thinking 
and tell their life story (McAdams 200 ; Sarbin I986). In a life story, the whole life and its coherence are linked to identity. Events are chosen and memorised through their emotional or motivational significance over the entire life ( $c f$. Hou, Miller and Kramer 2005). The life story of a person is under constant reconstruction and not told exactly the same way twice. The account changes in the sense that factual events and moral choices are built into a narrative and then interpreted and given meaning, although there is consistency in the main themes and the key anecdotes. Generally, this is also what the narrator aims at, reflecting a need to create a meaningful story out of all the seemingly disparate events and choices in life (McAdams I995).

Self 3 is made up of the many social constructions of the self that people may wish to display, e.g. by adopting the role of a caring hostess or an intellectual academic. These external social selves or personae refer to the person's interplay with their social sphere and may attenuate during the course of AD. The loss depends, however, less on neurological damage than on having few opportunities to express these aspects of self, or the lack of other people's readiness to allow and affirm these manifestations of the personality of the person (Sabat and Harré 1992).

\section{Life story and view of life}

Taylor argued that the life story of a person is created in an ethical space:

Human beings always have a sense of self, in the sense that they situate themselves somewhere in ethical space. Their sense of who they are is defined partly by some identification of what are truly important issues, standards, goods, or demands; and correlative to this, by some sense of where they stand relative to these or where they measure up on them or both. (1991: 306)

Despite inevitable cognitive decline, this also holds for people with AD. In a study of the narratives of two rural American older women - one of them suffering from dementia - both narrated their life story according to their dominant personal and cultural values. The sense of identity of the older woman with dementia remained and was still expressed through her co-constructed memories (Schenk et al. 2002). The expression 'coconstructed' underlines the observation that a life story is always constructed in interplay with others (Sabat and Collins I999; Surr 2006). During the progression of $\mathrm{AD}$, this interplay and a care-giver's ability to trigger and co-construct memories become increasingly vital for the preservation of identity (Cohen-Mansfield, Golander and Arnheim 2000; Lazarus, Cohler and Lesser 1996; Sabat and Harré 1992).

The space within which people create their life story and understand their identity consists of more than ethical values. Human beings aspire to 
be recognised, appreciated, respected or loved by others, and seek pleasure and development in the company of others. Their personal life values - however altruistic - are also means to that end. They reflect a common human need to belong, to be part of a group. At an early stage, when parents introduce their small child to their ethical framework, this is done within a basic emotional space. Trust, mistrust, hope and other basic emotions exist in the mind of the child before cognition and ethical values require the mastering of words and the communication of symbols (Erikson and Erikson 1997). There are good reasons to believe that this basic emotional space prevails longer into the process of dementia than their cognitive resources. Mills indicated that 'there is a certain strength and durability in the emotional autobiographical memories of informants' that is not apparent in other aspects of memory (1997: 696). These circumstances lead to the assumption that people's sense of identity does not disappear when the ability to articulate their life story is disturbed or when thoughts become confused. Sense of identity, just as view of life, is about central values and emotions as well as memory.

\section{Methods and the participants}

We invited 23 people who had been diagnosed one to two years earlier with mild to moderate $\mathrm{AD}$ to participate in the study, and 2I (I2 women and nine men) agreed. Ten test interviews had provided information about which abilities would be needed to take part in the interviews. It was important that the participants did not experience insurmountable difficulties, either when trying to memorise the early phases of their life $(c f$. Addis and Tippett 2004), or when verbally expressing their memories or narrative. Health professionals at a memory clinic and at two day-care centres in different parts of Sweden were informed of these inclusion criteria. They were also informed that the main diagnosis of the participants was to be mild or moderate AD. Apart from one woman aged 6r years, the participants were aged from 73 to 89 years. Two-thirds (I4) had from six to nine years of school education, and seven had received higher education. Their general level of cognitive and practical abilities was estimated by a close relative or care-giver using the Functional Assessment Staging Scale (FAST) as summarised in Table I (Reisberg I988).

\section{Data collection}

Believing that the best way to understand people's views of life is to listen to their life stories, it was decided to conduct narrative interviews. 
T A в L E I. Reisberg's Functional Assessment Staging

\begin{tabular}{ll}
\hline Stage & \multicolumn{1}{c}{ Indicators } \\
\hline I & No difficulties, either subjectively or objectively. \\
2 & Complains of forgetting location of objects; subjective work difficulties. \\
3 & Decreased job functioning evident to co-workers; difficulty in travelling to new locations. \\
4 & Decreased ability to perform complex tasks, e.g. planning dinner for guests, \\
& handling finances and shopping. \\
5 & Requires assistance in choosing proper clothing. \\
6 (a) & Difficulties with putting clothing on properly. \\
6 (b) & Unable to bathe properly; may develop fear of bathing. \\
6 (d) & Inability to handle mechanics of toileting, e.g. forgets to flush, doesn't wipe properly. \\
6 (e) & Erinary incontinence. \\
7 (a) & Ability to speak limited (one to five words a day). \\
7 (b) & All intelligible vocabulary lost. \\
7 (c) & Not ambulant. \\
7 (d) & Unable to sit up independently. \\
7 (e) & Unable to smile. \\
7 (f) & Unable to hold head up.
\end{tabular}

Note: In the present study, nine participants were estimated as at Stages $4-5$, and I2 at Stages 6 (a-d). Source: Reisberg (I988).

The participants were asked to narrate their life story starting with childhood and youth. The meaning that they attached to their view of life was explored by asking: What do you value in life, what do you consider most important and what do you feel happy or proud or perhaps sad about? The interviewers made no explicit references to religion, spirituality or philosophy because this might have conveyed a narrow impression of 'view of life'. Only when the narrative had come to a halt were followup questions asked. They had two purposes:

- To encourage reflections on what the participants had mentioned, e.g. about relatives (including role models and roles of parents), pastimes, work and society, all of which topics help people focus on and express their view of life.

- To make memories easier to recall. To illustrate, a follow-up question might focus on emotionally-powerful memories, such as 'What did you like the most about going to school?' or 'What did you dislike the most?' ( $c f$. Feil and De Klerk Rubin 2002).

The interviews took place at two day-care centres where the participants were regular guests and in three cases in the participants' homes. A secluded and quiet surrounding was chosen because people with AD may have trouble selecting from incoming stimuli. The interviews lasted $45^{-75}$ minutes and were tape-recorded and transcribed verbatim. Non-verbal communication (e.g. laughter and silence) were noted in the recordings. 


\section{The interpretation method}

A phenomenological hermeneutic method inspired by Ricoeur (I976) and developed by Lindseth and Norberg (2004) was used. Lived experiences are private but nevertheless when telling a life story, the narrator makes the meaning of his or her lived experiences public and possible for others to understand. This form of understanding can be achieved through dialectic transitions, from a 'naïve understanding' to explanation, and from explanation to a new understanding (Ricoeur 1976). Balancing between objective explanation and subjective understanding, the interpreter's task is to search for the meaning of the narrative, for the possibilities that are disclosed 'in front of the text'. The method is an adaptation of Ricoeur's thinking about texts that are generated by transcribing interviews. The interviewee is thought of as the principal author of the text with the interviewer as co-author (Lindseth and Norberg 2004). The interpretation attempts to see the broad picture and to recognise the interplay between interviewee and interviewer, the situation in time and culture, the background and the interpreter's prior understanding.

The interpretation had three steps. The first step, developing a 'naïve understanding', was achieved through an open-minded perusal of the interview text as a whole and by discussion among the authors. The second step required a more thorough reading and a structured thematic analysis. Questions related to view of life and to sense of identity were posed about the texts, i.e. the transcribed interviews ( $c f$. Lindseth and Norberg 2004: I49). The texts were divided into meaning units, being sentences or longer passages that seemed to have some connection to the research question: 'Is the view of life of the participants described as a vital aspect of their sense of identity?'

To achieve deeper understanding, the meaning units were first reflected upon and then written as statements. Whenever central personal values, the basic emotional attitudes or assumptions on man and the world were expressed, the interpretation focused on the questions: Were these aspects of the persons' view of life also sensed as aspects of their sense of identity? Did the participants express personal values (e.g. being fair, courageous or caring) as attributes that characterised them? Did they sense that their strong spiritual or political beliefs characterised them? Did they sense that their basic emotional attitudes (e.g. being optimistic or melancholy) characterised them? Did they sense that their view of life had been a vital aspect of their sense of identity for most of their life? After re-reading the interview texts several times and following reflection, the texts were compared, condensed, abstracted and assembled into themes and subthemes. The results of the structural analysis, that is the identified themes, 
were then compared with our naïve understanding and discussed among the authors. The third step of the interpretation was to produce a synthesis from the 'naïve' understanding, from the themes and the interpreters' preconceptions, and from the research literature. For conceptual clarification, the synthesis was related to relevant theoretical concepts, such as Jeffner's (I988 a) definition of an individual view of life, and Harré's (I99I, I998) definition of self.

\section{Ethical considerations}

It is impossible to foresee all possible consequences of a participant being interviewed about her or his life story and view of life. Feelings of regret or fears of having revealed too much may emerge, or certain memories may prove to be more painful than expected. Moreover, an interviewer cannot establish with absolute certainty when a person is 'fully informed' (Pratt 2002). When people with $\mathrm{AD}$ are asked to participate, the ethical issues are more complicated. Aside from the risk that they are not able to realise fully what they have agreed to, there is the possibility that the demands of the situation make them feel inadequate and painfully aware of their failing abilities. If the interviews are performed respectfully and in a friendly atmosphere, however, it is more likely that the informants will appreciate having their voices heard, and will feel valued as being regarded as capable persons and taken seriously (Dewing 2002; Keady and Gilliard 1999). This reasoning is in line with the observations and recommendations of authors that have taken the person-centred approach, that being supportive and of avoiding excessive demands affirms the value of the participants and enhances their communicative resources (Bohling I99I; Normann et al. 2005; Tappen et al. 1999). On the other hand, interactions that make unwelcome demands on participants with $\mathrm{AD}$ will be disruptive, primarily because of their frail self-confidence and disturbed reality orientation.

Before the interviews, verbal and written information was given to the participants, their closest relative and their professional care-givers. The purpose of the interviews was explained first by a professional caregiver or a close relative and then by the interviewer. The participants were informed of their right to withdraw from the study at any time without giving a reason. To protect their privacy, they were informed that no identifying information would be published in the study's reports. The participants and their closest relative gave their permission for the interviews. A trusted family member or professional care-giver was physically nearby after each interview. During one interview, a participant became restless, which caused a temporary interruption, but the interview was 
soon concluded without further incident. The participants, relatives and professional care-givers were invited to contact the interviewer after the interview if they wished to do so, but this did not happen. ${ }^{1}$

\section{Implementation of the interpretation}

The analysis of the participants' responses led to the construction of several themes and sub-themes. The perspectives we arrived at are of course not the only possible constructions. An essential part of the phenomenological hermeneutic method is to acknowledge that other interpretations are possible and valid, and that they can be very different from those reported. Individual personality traits, for example, are often closely connected to aspects of the individual's view of life. Someone who in view of life terms is successfully expressing central values, such as courage or willingness to care for others, might be described in psychological terms as having a courageous or caring personality.

\section{The findings: the naïve understanding}

Because their verbal abilities were defective, the participants' stories generally lacked detail, but by telling their life story they also narrated their view of life. One did not, however, explicitly narrate his view of life as personal values and emotions. Although he described co-operation and solidarity as important values, he seemed to look upon them as steadfast laws of nature and society rather than personal values. The participants' central personal values and basic emotional attitudes were disclosed as vital aspects of their sense of identity, and understood as their beliefs about their life history and characterising attributes ( $c f$. Harré I998).

One theme in the narratives was a sense of guidance through life by a spiritual power and its connections with the narrators' sense of identity. For instance, it was said (paraphrasing) that God has a plan for your life and provides you with personal characteristics that will make it possible for you to live according to this plan. Another recurring theme was the sense that life had been - and still is - meaningful. The experience of contracting AD had not seriously darkened the tellers' outlook on life as a whole, although the view that life had been meaningful but was now of little or no meaning was also conveyed. Some of the expressions suggested that the origins of the narrators' central values and basic emotional attitudes were in childhood and adolescence. A continuity of central values, basic emotional attitudes and sense of identity was conveyed despite the discontinuity of cognitive functions. 


\section{The findings of the structural analysis}

Analysis of and reflection on the meaning units suggested the following themes and sub-themes.

\section{Theme I: View of life as a vital aspect of sense of identity}

The participants disclosed their belief that components of their view of life, including central values, basic emotional attitudes and assumptions on reality, were vital aspects of their sense of identity.

\section{Sub-theme I.I: Personal attributes and view of life as vital aspects of sense of identity}

During most of her adult life, Mrs D had been working in a large kiosk selling food and other commodities. She said that her central values of hard work, keeping the family together and helping whenever it was needed were also those of her parents, and she described these along with her basic emotional attitudes as aspects of her sense of identity. She recognised that the attitude of others towards her self affected the connection between her view of life and her sense of identity. As Mrs D said, 'I think that I'm very lucky. Everyone is so kind to me. They consider me helpful, but that's only human. So I don't have many enemies (laughs) ... No, I'm lucky there'. Her line of thought was founded on two assumptions about her view of life that drew on personal experience: that there is a connection between being helpful and being treated kindly by others, and that in turn connected to a particular basic emotional attitude, namely feeling lucky. Mr O articulated a similar assumption that if you are a helpful person, people will be kind and helpful to you and you will do well in life. In his own words:

So ... people have been friendly ... and they have been kind and helpful. No one has hit me on the nose, not yet at least ... and I have a very excellent wife who I have had ... long enough (laughs).... No remarkable news ... but ... we live and we are together as much as there is ... nowadays we are doing well ... it's kids and kids of the kids as you say ... now you [we] have to help me with this [them] ... and of course you help.

Mr B also saw a connection between his basic emotional attitudes and his identity. In response to the question, 'Can you tell me something that has been important to you?' he replied, 'I belong to the happy people. If I saw a sad person ... I went over there [to him or her] and tried to make it better. ... I was light-hearted. ... I liked to sing'. Mrs M clearly stated that aspects of her sense of current identity, her personal characteristics, 
were present when she was a school child: 'I was an only child ... that's a kind of leadership training, I suppose. ... I was the kind of person to become a prefect, spokesperson for the school class, a person who would make a fuss if anyone was being bullied'. Her focus on the interpretation of her sense of identity did not emphasise the superficial resemblance between her early role as spokesperson for her school class and her adult role as speaker and member of the clergy, but rather focused on the sense that there was and still is a strong reason for her wish to speak up, i.e. her view of life.

By contrast, Mr G's basic emotional attitude was interpreted as melancholic. He was an adopted child, and when a teenager he tried to contact his biological father but was rudely rejected. His disappointment and bitterness over this rejection was still an intense part of his life story. Missing the unconditional support of his real parents was interpreted as a significant aspect of his identity.

Mr G: That was very, very hard. That was very hard! But I succeeded to ... manage my life anyway, you know.

Interviewer: Would you say that you're proud of that? Having managed despite everything?

Mr G: $\quad$ Yes. I haven't thought much of that ... but it could be that ... in certain situations you perhaps ... should be proud, at least.

Interviewer: Yes, because you did manage, didn't you?

Mr G: $\quad$ Oh, yes! Oh, yes! Oh, yes! I've never ... I haven't had ... even as much as a parking ticket, and that I'm proud of, but of course life was hard. Above all ... the most important of all things was that you knew ... those who had someone behind them ... I ... I had no one who was interested in me.

Mr G's comments illustrate the way in which the personal life view guides what people find important in their conception of reality and how it is interpreted. In narrating their life stories, the participants featured events in their lives about which they were proud or disappointed, and interpreted them as important elements of their life story and vital to their sense of identity. Mr G not only narrated disappointments in his early life but also explained that they had formed his outlook on life, and his views about other people and himself.

\section{Sub-theme 1.2: Sensing a guiding spiritual power in life and its relation to sense of identity}

Like most people in Sweden, nearly all the participants were members of the Church of Sweden (the state church until 2000). While religious or spiritual interpretations of their lives did not pervade the narratives, when the presence of a spiritual power in life was sensed, it was interpreted as 
essential to the speaker's sense of identity. During the interviews, some events that had occurred early in life and some choices that had been made were interpreted as 'meant to be', or were recognised as the work of a spiritual power. $\mathrm{Mr} \mathrm{O}$ put this view very well: 'Without being religiously ... engaged in any way, you get a feeling that ... the powers are helping you'. On similar lines, $\mathrm{Mr} \mathrm{R}$ vividly recalled a particular event and realisation:

I remember a long walk ... it was nearly night time ... and there was this somewhat elderly uncle who tried to enrol me in The Salvation Army to become an officer there, and he was quite possessed by the thought ... and in that direction my life was formed. ... I didn't join The Salvation Army, but there are bridges between their way of working and the way of working in the YMCA. ... I recall having given sermons in the Covenant Church in $\mathrm{S}$ [Swedish town] once or twice.

Mrs M also recalled a particular moment in her youth that she perceived as a turning point:

And suddenly, standing up there in the front, I felt ... this is the meaning with my life; this is where I'm supposed to be ... in the church. That was such an incredible experience. In the midst of the sad funeral it was just like a light from heaven.

\section{Theme 2: Valuing life in terms of meaning and connecting to one's sense of identity}

This theme was identified from disparate expressions by the informants, which ranged from those that affirmed a sense of meaning in life through more ambivalent expressions to a few nihilistic thoughts, but the positive, affirmative expressions were by far the most prevalent.

\section{Sub-theme 2.I: Sensing that life has been and still is meaningful and connected to identity}

The view that life on the whole had been and still was meaningful was the most prevalent, even if not always as strongly expressed as by Mrs U. Her life story disclosed a very positive outlook on life, and expressed the sense that her childhood had been a wonderful time and that she had been given the opportunity to live an active, meaningful life. Contracting AD had not seriously darkened her outlook on life as a whole. She recollected that:

I always had lots to do, as I wanted it to be [in life]. ... [I have] been a member of committees and associations ... during later years I worked with education.... I could manage so many things. ... I have had an enormously good life, thinking back. 


\section{Sub-theme 2.2: Feeling ambivalent about the meaningfulness of life and identity}

The view was also conveyed by two informants that life had been meaningful earlier but now had little or no meaning. This opinion was not generally tied to having $\mathrm{AD}$, however, but expressed a negative evaluation of what the narrators considered to be the unproductive lives of senior citizens. Two informants enunciated these views very well:

The way I would describe myself right now is that I feel like a rather unnecessary human being. ... I do nearly noth[ing] ... I have such a good time. There's a man who comes with my lunch every day and then the home service people come once a week and help me with shopping and washing my hair, and ... I'm satisfied with my life. (Mrs E)

Mrs E's frame of reference was a sense of no longer being able to do practical things and not being expected to contribute in any way. She was rather phlegmatic and cheerful about this, but like $\mathrm{Mr} \mathrm{V}$ she seemed to harbour an unfulfilled wish to make herself useful in some way despite her AD. Mr V's ambivalence appeared more deep-seated:

It's a rather carefree life being a pensioner. ... Right now I can't say that there is any meaning [in life] and I can say honestly that I wouldn't mind so much leaving the earthly [life]. ... I wouldn't become all that mad if I was going to die.

Mrs $\mathrm{S}$ gave one of the most candid and rich assessments of the meaning that she perceived in her life. She had experienced tragic events, especially the death of a teenage son in a car accident. She described her marriage as 'ordinary', for although she and her husband had worked well together in the family business, they had not had a 'deeper relationship'. Still, looking back, she described her life as meaningful. Her conception of good and bad was sensible and practical. Her AD had not dissipated her downto-earth wisdom, nor a belief that she still possessed the personal characteristics required to manage most of what life might bring. In her own words:

There have been sad things and happy things but ... I don't consider life meaningless. Not even if things go against you ... and if they do go against you, you have to fight all the way ... so it's been meaningful ... but not when he died. ... Accidents go deep, you know, and they leave their mark; and happy events leave their mark ... and it has to be like that in life. Of course, you have to be unhappy to be able to be happy too.... There is nothing you can't manage. ... Well, I can't say nothing, but much of it you can manage.

\section{Theme 3: Expressing of continuity in central values, emotional attitudes and identity}

During the course of a person's life, the meaning of their lived experiences may change considerably, but no changes of the participants' underlying 
views of life were expressed during the interviews. Instead, a sense of continuity of the participants' central values and basic emotional attitudes throughout life was prevalent in the life stories.

\section{Sub-theme 3.I: Expressing continuity of central values and sense of identity}

Not one expression during the interviews indicated that the participants' former central values had been abandoned. Thinking back on his working experience, $\mathrm{MrO}$ saw coherence in the content and meaning of his life. In his various posts, his personal skills and central values had always been useful, he sensed. As he said, '[I've] been in the same toolbox, so to say, in all my jobs ... solving problems and ... making decent people know that they are decent'. Mrs M had been a member of the clergy. Despite the recent cognitive losses that had adversely affected her professional abilities, she sensed that her life story was very closely connected with the Judeo-Christian narrative that had been with her since childhood:

In a way, I immediately felt at home as she [school teacher] started telling ... the stories of the patriarchs, the whole Old Testament, it's still my treasure, and it's sad now when I've forgotten so much and can't find it as naturally as I did earlier, but I've been lecturing on characters in the Old Testament all my adult life and I love that. Don't give me any blasted docu-soap - it's already there [in the OT], all of it. We don't need any more.

Mr R also related his Christian faith to his childhood:

[My mum] was as pious as any talented human being can be.... She gave character to our family, and my dad who did not have the same warm faith in God ... he had to sit down with us every evening. ... I remember our big dad who was a policeman. He'd sit at the short end of the table folding his large hands ... and she would read the daily prayer from one of those prayer books she had ... they were fine moments, very fine moments.

Sub-theme 3.2: Expressing continuity of basic emotional attitudes and sense of identity

Reflecting on their emotional state of mind, continuity over their lifespan also pervaded the informants' expressions. When Mrs T was asked, 'Is there anything in your life that you are especially happy about?' she replied, 'All my life ... everything has been so wonderful'. When the interviewer then queried, '[Are] you are happy about your life?' she affirmed, 'Yes, even now, actually'. Mrs B sensed that her lightheartedness had been with her when she was a child: 'I guess I'm a bit light, too (laughed) ... I don't decline very deep'. 


\section{Discussion and synthesis}

In the frames of their life stories, the participants' views of life were understood to be a vital aspect of their sense of identity. McAdams (I995, 200I) asserted that telling your life story is a process through which you seek to provide your life with unity and purpose. One might think that being diagnosed with $\mathrm{AD}$ would put an end to all hope of leading a life with unity and purpose, but when looking back on their lives, most of the informants instead expressed both a sense of meaningfulness and a sense of continuity in central values and basic emotional attitudes. They also mentioned experiencing problems with memory and concentration. Cognitive functions and abilities deteriorate with the progression of AD. Even those cognitive functions and abilities that earlier have been important components of the self-image are no longer functioning properly, but despite these cognitive limitations, identity was sensed to prevail and the participants' expressions interpreted their view of life as a vital component of their sense of identity.

This analysis and interpretation has concentrated on those aspects of the participants' accounts that related their life stories and views of life (Self 2). Their expressions had clear indications of the ways in which they looked upon themselves as subjects (Self I), and some referred to social roles (Self 3). The attitude of others was sensed to affect their sense of identity. Both their words and their body language indicated that they felt unthreatened and at ease in the interview situation. Their expressions conveyed their senses of the connections between one's view of life, the attitudes of others towards them, and their senses of identity (Self 2 and 3 ).

People with AD experience increasingly severe changes, but their accounts of their views of life were characterised by continuity. These findings correspond with those from studies of continuity and change (McLean 2008) and with McAdams's (I995, 200I) model of narrative identity. 'Identity in adulthood is an inner story of the self that integrates the reconstructed past, perceived present and anticipated future to provide a life with unity, purpose and meaning' (McAdams I995: 365). In a longitudinal study of ageing and adaptation, Atchley (1999) found that most of his respondents perceived a continuity of their basic values over time. The present study seems to support recent critical revisions of Bury's (I982) theory of biographical disruption in chronic illness. As Williams (2000: 50) put it, 'compared to socially-set standards and cultural prescriptions of normality ... the lives of these individuals may appear profoundly disrupted. Yet, phenomenologically and existentially speaking, it remains the case that these biographies have not, in any real or 
significant sense, shifted. Continuity rather than change remains the guiding principle'. As expected, not all the narratives in the present study expressed happiness and pride. A few expressions of bitterness and disappointment were observed as was the feeling that life at present was rather meaningless.

Despite all this, it remains puzzling why such a pervasive and grim life change as $\mathrm{AD}$ was not a significant theme in their life stories. If the interviews had instead been directed toward the specific experience of contracting $\mathrm{AD}$, the narratives would probably have been more negative. From a view of life perspective, the taken-for-granted features of everyday life had been shattered for them at least one or two years earlier ( $f f$. Bury I982). Painful 'why questions', about the existential meaning of the tragic diagnosis had probably entered their mind, but such questions were not raised during the interviews. Did the interviews about their life story and view of life provide an opportunity for the participants to put their $\mathrm{AD}$ to one side, and to narrate their story about which they were proud? Were they trying to uphold a sense of continuity and defending their sense of identity, even against their better judgement? Did they unconsciously present a deceitful but self-assertive narrative?

This study has not searched for objective truth but for meaning, which we acknowledge is in some respects co-created between the narrator and the interviewer. Their interactions inevitably influence the atmosphere and outcomes of any interview. Subtle and sub-conscious messages may be conveyed about which topics are allowed or preferred, and which are not. In this case, the interviewer was experienced in conversational therapy and had received psycho-therapeutic training. While listening to the subjective truth of persons telling their life story, he tried to create a friendly and respectful atmosphere, and expressed a positive interest in their life stories. Attention was not drawn to actual or possible inaccuracies. The favourable finding of the present study may have arisen from the positive overall ambience of the interview. By contrast, being subjected to a Mini Mental-State Examination (MMSE) during an interview, which focuses on one's deficits rather than strengths, can be a serious blow to self-esteem and a threat to sense of identity (Hellström et al. 2007). The significance of stereotype threat in the memory performance of older adults has been shown (Chasteen et al. 2005; Hess et al. 2003). In the present study there was no such actual or imminent threat. The participants were already aware of their diagnosis and had been informed that the interview was not part of a diagnostic process.

It is plausible that people with $\mathrm{AD}$ (and others) sometimes construct a life story that seems overly positive and meaningful in the eyes of others. Striving for some sense of meaning and unity in a life that is threatened 
by disintegration is a likely and reasonable strategy. From an ethnographic study, Orulv (2008) observed among people with dementias the process of meaning-making in social interactions. A remaining ability to maintain some sort of continuous sense of self and continuity with previous life history was observed, and sense-making, self-making and world-making (cf. Bruner 200I) continued despite severe memory loss and disorientation in time and space. It seems reasonable that this sense of self and worldmaking was based largely on the central values, the cognitive assumptions and the basic emotional attitudes that constituted the person's view of life.

\section{Gonclusions and implications}

A process of $\mathrm{AD}$ presents serious threats to a person's sense of identity. The cognitive resources for communicating knowledge of the person you are and that you once were diminish increasingly over time. In this study, the views of life of 2I people with mild to moderate $\mathrm{AD}$ were interpreted as being a vital aspect of their sense of identity, understood as their beliefs about both their life history and the attributes that characterised them. People with knowledge of the life story and memories of a person with AD can help to trigger dormant memories and stimulate reminiscence (Gibson 2005; Harrison 1993; Schenk et al. 2002). If they have been part of the life of the person with $\mathrm{AD}$, they can reawaken faint memories by finding effective retrieval cues (cf. Stopford et al. 2007). Crichton and Koch (2007) used a participatory story-telling approach when interviewing seven people in the social network of a woman with dementia disease. Their stories were then woven into one narration. The authors saw this joint narrative effort - telling 'about', 'for' and potentially 'with' a person with dementia - as interactions that reproduced and reconfirmed her self. Recent work by Nolan and others on relationship-centred care has highlighted the importance of building upon mutual recognition in developing unrealised potentialities of the people with dementia, their family carers and professional care-givers (Nolan et al. 2003; Ryan et al. 2008). Working in a reflective and purposeful way with such triads includes recognising the importance of knowing people with dementia's views of life and of drawing on these to help them preserve their sense of identity. Their view of life should ideally be heard in their own voices. Their life stories and their view of life, however, are intertwined with those of their family carers; when their own voices become silent or muddled, listening to the 'intertwined narrative' of family carers becomes an important part of relationship-centred care. 


\section{Acknowledgements}

The participants, who so willingly allowed us to interview them, sharing their life stories and their view of life, occupy a special place in our hearts. Some of them have since travelled to an unknown address, leaving their bodies behind, but their life stories vividly live on. 'He who has been, henceforth cannot not have been: henceforth this mysterious and profoundly obscure fact of having been is his viaticum for all eternity' (Jankélévitch I974: 275). We also wish to thank Ersta diakoni, the Hedlund Foundation and The Swedish Order of Freemasons for funding the research on which this paper is based.

\section{NOTE}

I Ethical approval was obtained from the Regional Ethical Review Board in Uppsala, Sweden (approval 2004: Ö-319).

\section{References}

Addis, D. and Tippett, L. 2004. Memory of myself: autobiographical memory and identity in Alzheimer's disease. Memory, 1 2, I, 56-74.

Andersson, L. 2006. Några filosofiska kommentarer till livsåskådningssamtal i vården [Some philosophical comments on talking about view of life in health care]. In Silverberg, G. (ed.), Nya vägar i vardetiken [New Ways in Health Care Ethics]. Studentlitteratur, Lund, Sweden, I5I-77.

Atchley, R. I999. Continuity and Adaptation in Aging: Creating Positive Experiences. Johns Hopkins University Press, Baltimore, Maryland.

Bohling, H. R. I99I. Communication with Alzheimer's patients: an analysis of caregiver listening patterns. International Fournal of Aging and Human Development 33, 4, 249-67.

Bruner, J. 200I. Self-making and world-making. In Brockmeier, J. and Carbaugh, D. (eds), Narrative and Identity: Studies in Autobiography, Self and Culture. John Benjamins, Amsterdam, $\mathrm{I}-22$.

Bury, M. I982. Chronic illness as biographical disruption. Sociology of Health and Illness, 8, 2, $167-82$.

Chasteen, Al, Bhattacharyya, S., Horhota, M., Tam, R. and Hasher, L. 2005. How feelings of stereotype threat influence older adults' memory performance. Experimental Aging Research, 31, 3, 235-60.

Clare, L. 2003. Managing threats to self: awareness in early stage Alzheimer's disease. Social Science and Medicine, 57, 6, I017-29.

Cohen-Mansfield, J., Golander, H. and Arnheim, G. 200o. Self-identity in older persons suffering from dementia: preliminary results. Social Science and Medicine, 5I, 33, 38I-94.

Coleman, P. 2005. Uses of reminiscence: functions and benefits. Aging and Mental Health, 9, 4, 29I-4.

Coleman, P. and Mills, M. 200r. Philosophical and spiritual perspectives on dementia. In Cantley, C. (ed.), A Handbook of Dementia Care. Open University Press, Buckingham, $\mathrm{UK}, 62-76$.

Crichton, J. and Koch, T. 2007. Living with dementia: curating self-identity. Dementia, 6, $3,365-8$ I.

Dewing, J. 2002. From ritual to relationship: a person-centred approach to consent in qualitative research with older people who have dementia. Dementia, I, 2, I57-7I. 
Elliot, H. I997. Religion, spirituality and dementia: pastoring to sufferers of Alzheimer's disease and other associated forms of dementia. Disability and Rehabilitation, r9, Io, 435-4I.

Erikson, E. and Erikson, J. 1997. The Life Cycle Completed. Extended version with new chapters on the ninth stage of development, Norton, New York.

Everett, D. 1996. Forget Me Not: The Spiritual Care of People with Alzheimer's Disease. Inkwell, Edmonton, Canada.

Fazio, S. and Mitchell, D. 2009. Persistence of self in individuals with Alzheimer's disease: evidence from language and visual recognition. Dementia, 8, I, 39-59.

Feil, N. and De Klerk Rubin, V. 2002. The Validation Breakthrough. Health Professions Press, Baltimore, Maryland.

Fontana, A. and Smith, R. I989. Alzheimer's disease victims: the 'unbecoming' of self and the normalization of competence. Sociological Perspectives, 32, I, 35-46.

Gibson, F. 2005. Fit for life: the contribution of life story work. In Marshall, M. (ed.), Perspectives on Rehabilitation and Dementia. Jessica Kingsley, London, I75-9.

Harré, R. 199I. The discursive production of selves. Theory and Psychology, I, I, 5I-63.

Harré, R. I998. The Singular Self: An Introduction to the Psychology of Personhood. Sage, Thousand Oaks, California.

Harrison, G. I993. Personhood, dementia and the integrity of a life. Canadian Fournal on Aging, I 2, 4, 428-40.

Hellen, C. R. I994. The confused worshiper with dementia, the clergy and the caring congregation. Aging and Spirituality (Newsletter of the American Sociological Association Forum on Religion, Spirituality and Aging), 6, I, I-8.

Hellström, I., Nolan, M., Nordenfelt, L. and Lundh, U. 2007. Ethical and methodological issues in interviewing persons with dementia. Nursing Ethics, I 4, 5, 6o8-19.

Hess, T. M., Auman, C., Colcombe, S. J. and Rahhal, T. A. 2003. The impact of stereotype threat on age differences in memory performance. Fournal of Gerontology: Psychological Sciences, 58, I, 3-II.

Hou, C. E., Miller, B. L. and Kramer, J. H. 2005. Patterns of autobiographical memory loss in dementia. International Fournal of Geriatric Psychiatry, 2o, 9, 809-I5.

Hughes, J. C., Louw, S. J. and Sabat, S. 2006. Dementia: Mind, Meaning and the Person. Oxford University Press, New York.

Jankélévitch, V. I974. L'irreversible et la nostalgie [The Irreversible and Nostalgia]. Flammarion, Paris.

Jeffner, A. 1978. Livsåskådningsforskning [Research on Views of Life]. Teologiska institutionen, Uppsala Universitet Department of Studies in Faiths and Ideologies, Uppsala University], Uppsala, Sweden.

Jeffner, A. I988 $a$. Att studera livsåskådningar [Studying views of life]. In Bråkenhielm, C. R. (ed.), Aktuella livsåskådningar [Viewes of Life of Today]. Part I, Doxa, Lund, Sweden, I I- 2 I.

Jeffner, A. I988 $b$. Livsåskådningar i Sverige: Inledande projektpresentation och översiktlig resultatredovisning [Views of life: preliminary presentation of project and overview of results]. Unpublished paper, Uppsala Universitet, Uppsala.

Jolley, D., Benbow, S., Grizell, M., Willmott, S., Bawn, S. and Kingston, P. 2005. Spirituality and Faith in Dementia. Presentation at a meeting of the Faculty of Old Age Psychiatry and the Special Interest Group for Spirituality and Mental Health, Royal College of Psychiatrists, London, I4 December.

Jones, G. and Miesen, B. (eds) 1997. Care-giving in Dementia: Research and Applications. Routledge, London.

Kallenberg, K., Bråkenhielm, C. R. and Larsson, G. I996. Tro och värderingar i go-talets Sverige: Om samspelet livsåskådning, moral och hälsa [Beliefs and Values in Sweden in the Ig9os: On the Interplay of Life Views, Morals and Health]. Libris, Örebro, Sweden. 
Karner, T. and Bobbit-Zeher, D. 2006. Losing selves: dementia care as disruption and transformation. Symbolic Interaction, 28, 4, 549-70.

Keady, J. and Gilliard, J. I999. The early experiences of Alzheimer's disease: implications for partnership and practice. In Adams, T. and Clarke, C. (eds), Dementia Care: Developing Partnerships in Practice. Baillière Tindall, London, 227-56.

Kihlgren, M. 1992. Integrity in Promoting Care of Demented Patients. Umeå University Press, Umeå.

Kitwood, T. 1993. Towards a theory of dementia care: the interpersonal process. Ageing \&尺 Society, 13, I, 51-67.

Kitwood, T. I997. Dementia Reconsidered: The Person Comes First. Open University Press, Buckingham, UK.

Kitwood, T. and Bredin, K. I992. Towards a theory of dementia care: personhood and well-being. Ageing \& Society, 1 2, 3, 269-87.

Klein, S. B., Chan, R. L. and Loftus, J. I999. Independence of episodic and semantic selfknowledge: the case from autism. Social Cognition, I 7, 44, 413-36.

Klein, S. B., Cosmides, L. and Costabile, K. A. 2003. Preserved knowledge of self in a case of Alzheimer's dementia. Social Cognition, 2 I, 2, I57-65.

Klein, S. B., Cosmides, L., Costabile, K. A. and Mei, L. 2002. Is there something special about the self? A neuropsychological case study. Fournal of Research in Personality, 36, 5, 490-506.

Lazarus, L., Cohler, B. and Lesser, J. 1996. Self-psychology: its application to understanding patients with Alzheimer's disease. International Psychogeriatrics, 8, supplement 3, $253^{-8 .}$

Lindseth, A. and Norberg, A. 2004. A phenomenological hermeneutical method for researching lived experience. Scandinavian fournal of Caring Sciences, I 8, 2, I45-53.

McAdams, D. P. I995. What do we know when we know a person? Journal of Personality, $\mathbf{6}_{3}$, $3,365-96$.

McAdams, D. P. 200I. The psychology of life stories. Review of General Psychology, 5, 2, I00-22.

McFadden, S., Ingram, M. and Baldauf, C. 2000. Actions, feelings and values; foundations of meaning and personhood in dementia. Fournal of Religious Gerontology, I I , 3-4, 67-86.

McLean, K. 2008. Stories of the young and the old: personal continuity and narrative identity. Developmental Psychology, 44, I, 254-64.

Melia, S. I999. Continuity in the lives of elder Catholic religious women. International Fournal of Aging and Human Development, 48, 3, I75-89.

Mills, M. A. I997. Narrative identity and dementia: a study of emotion and narrative in older people with dementia. Ageing E Society, I 7, 6, 673-98.

Nolan, M., Lundh, U., Grant, G. and Keady, J. (eds) 2003. Partnerships in Family Care: Understanding the Caregiving Career. Open University Press, Maidenhead, UK.

Normann, H. K., Henriksen, N., Norberg, A. and Asplund, K. 2005. Lucidity in a woman with severe dementia related to conversation: a case study. Fournal of Clinical Nursing, I4, 7, $89 \mathrm{I}-6$.

Orona, C. J. I990. Temporality and identity loss due to Alzheimer's disease. Social Science and Medicine, 3o, II, I247-56.

Örulv, L. 2008. Fragile Identities, Patched-up Worlds: Dementia and Meaning Making in Social Interaction. Linköping Dissertations on Health and Society, Linköping University, Sweden.

Penrod, J., Yu, F., Kolanowski, A., Fick, D., Loeb, S. and Hupcey, J. 2007. Reframing person-centred nursing care for persons with dementia. Research and Theory for Nursing Practice, 2 I, I, 57-72.

Pratt, R. 2002. 'Nobody's ever asked how I felt.' In Wilkinson, H. (ed.), The Perspectives of People with Dementia: Research Methods and Motivations. Jessica Kingsley, London, I65-82.

Rathbone, C., Moulin, C. and Conway, M. 2008. Self-centred memories: the reminiscence bump and the self. Memory and Cognition, 36, 8, I403-I4. 
Reisberg, B. I988. Functional assessment staging (FAST). Psychopharmacology Bulletin, 24, $4,653-9$.

Richards, M. I99o. Meeting the spiritual needs of the cognitively impaired. Generations, I4, $63-4$.

Ricoeur, P. I976. Interpretation Theory: Discourse and the Surplus of Meaning. Christian University Press, Fort Worth, Texas.

Ronch, J. L. I996. Mourning and grief in late life Alzheimer's dementia: revisiting the vanishing self. American Journal of Alzheimer's Disease, I I , 4, 25-8.

Ryan, T., Nolan, M., Reid, D. and Enderby, P. 2008. Using the senses framework to achieve relationship-centred care services: a case example. Dementia, 7, I, 7I-93.

Sabat, S. 200I. The Experience of Alzheimer's Disease. Blackwell, Oxford.

Sabat, S. 2007. Untangling selfhood: the history and experience of Alzheimer's disease. Presentation at a conference to mark the Iooth anniversary of Alzheimer's disease as a diagnostic category, Pennsylvania State University, University Park, Pennsylvania, 29-3i March.

Sabat, S. and Harré, R. I992. The construction and deconstruction of self in Alzheimer's disease. Ageing \& Society, I 2, 4, 443-6I.

Sabat, S. and Collins, M. I999. Intact social, cognitive ability, and selfhood: a case study of Alzheimer's disease. American Fournal of Alzheimer's Disease, I4, I, I I-I9.

Sarbin, T. R. 1986. Narrative Psychology: The Storied Nature of Human Conduct. Praeger, New York.

Schenk, D., Davis, B., Peacock, J. R. and Moore, L. 2002. Narratives and self-identity in later life: two rural American older women. Fournal of Aging Studies, I6, 4, 40I-I3.

Staude, J. 2005. Autobiography as spiritual practice. Fournal of Gerontological Social Work, 45, $3,249-69$.

Stopford, C. L., Snowden, J. S., Thompson, J. C. and Neary, D. 2007. Distinct memory profiles in Alzheimer's disease. Cortex, 43, 7, 846-57.

Stuckey, J. 2003. Faith, aging, and dementia: experiences of Christian, Jewish and non-religious spousal caregivers and older adults. Dementia, 2, 3, 337-52.

Surr, C. 2006. Preservation of self in people with dementia living in residential care: a socio-biographical approach. Social Science and Medicine, 62, 7, I720-30.

Tappen, R. M., Williams, C., Fishman, S. and Touhy, T. i999. Persistence of self in advanced Alzheimer's disease. Image: Fournal of Nursing Scholarship, 3 I, 2, I2 I-5.

Taylor, C. I99I. The dialogical self. In Hiley, D. (ed.), The Interpretive Turn: Philosophy, Science, Culture. Cornell University Press, Ithaca, New York, 304-I4.

Webb, G. 200I. Intimations of the great unlearning: inter-religious spirituality and the demise of consciousness which is Alzheimer's. Cross Currents, 5I, 3, 324-37.

Westius, A., Andersson, L. and Kallenberg, K. 2009. View of life in persons with dementia. Dementia, 8, 4, 48I-99.

Williams, S. 2000. Chronic illness as biographical disruption or biographical disruption as chronic illness? Reflections on a core concept. Sociology of Health and Illness, 22, I, 40-67.

Woods, R. T. 200I. Discovering the person with Alzheimer's disease: cognitive, emotional and behavioural aspects. Aging and Mental Health, 5, I, 7-I6.

Accepted 22 March 20IO; first published online 20 Fuly 2010

Address for correspondence:

Anders Westius, School of Health and Medical Sciences, Örebro University Hospital, SE 70185 Örebro, Sweden.

E-mail: anders.westius@telia.com 